\title{
Beverly Brodsky Responds
}

To the Editor:

In response to Carla Wills-Brandon's concerns about the possibility that negative reactions following the psychomanteum experimentation are caused solely by objective, external triggers, I reiterate the final statement in my previous letter (Brodsky, 1998) that cause and effect cannot be proven in these cases. I wish only to echo Raymond Moody's point in the closing pages of Reunions (Moody and Perry, 1993) that this is truly a Pandora's box that should be respected as such, and not approached with an atmosphere of naive playfulness, which I feel he encourages.

Pharmaceuticals like tobacco and peyote were used as sacraments for centuries in Native American traditions with no evidence of addiction, abuse, or emotional harm, because their culture brought the user safely through what might have been dangerous experiences for the novice. Millennia of denial and suppression have cut off Western culture from knowledge used by the ancients in their prophetic temples. The psychomanteum is a powerful window peering through a glass darkly at the abyss between life and death. Its use would be more responsible in a healing, supportive context such as Moody has arranged in his Theater of the Mind or as part of transpersonal therapeutic grief work.

\section{References}

Brodsky, B. (1998). Risks of psychomanteum experimentation [Letter]. Journal of Near. Death Studies, 17, 141-142. 
Moody, R. A, and Perry, P. (1993). Reunions: Visionary encounters with departed loved ones. New York, NY: Villard.

Beverly Brodsky

12031 Via Felicia

El Cajon, CA 92019

e-mail: bevbrodsky@aol.com 